\title{
Negative stress echocardiographic responses in normotensive and hypertensive patients with angina pectoris, positive exercise stress testing, and normal coronary arteriograms
}

\author{
E G Zouridakis, I D Cox, X Garcia-Moll, S Brown, P Nihoyannopoulos, J C Kaski
}

\begin{abstract}
Objectives-To systematically compare the results of dobutamine stress echocardiography in matched groups of hypertensive and normotensive patients with anginal chest pain and normal coronary arteriograms (CPNA).

Setting-University hospital.

Subjects-33 patients with exertional anginal chest pain, a positive exercise stress ECG, and a completely normal coronary arteriogram; 17 had a history of systemic hypertension (14 women; mean (SD) age 57 (6) years), and 16 had no hypertensive history (12 women; age 54 (9) years)

Methods-Ambulatory ECG monitoring, dobutamine stress echocardiography, and thallium201 single photon emission computed tomography (SPECT) were performed in all subjects.

Results-All patients had normal left ventricular systolic function at rest and none fulfilled the criteria for ventricular hypertrophy. Eight normotensive patients and 10 hypertensive patients had perfusion abnormalities on thallium SPECT $(p=0.61)$. Dobutamine infusion reproduced anginal pain in seven normotensive and seven hypertensive patients $(\mathrm{p}=0.88)$. ST segment depression was also recorded in eight normotensive patients and seven hypertensive patients $(\mathrm{p}=0.61)$. No patient in either group developed regional wall motion abnormalities during dobutamine stress echocardiography.

Conclusions-Neither hypertensive nor normotensive CPNA patients developed regional wall motion abnormalities during dobutamine stress echocardiography, despite the high prevalence of scintigraphic perfusion defects in both groups and the presence of chest pain and ST segment depression. Thus myocardial ischaemia was not present in either group, or else dobutamine stress echocardiography is insensitive to ischaemia caused by microvascular dysfunction.

(Heart 2000;83:141-146)
\end{abstract}

Keywords: dobutamine stress echocardiography; microvascular angina; hypertension; syndrome $\mathrm{X}$

Both hypertensive and normotensive patients may present with anginal chest pain despite completely normal coronary arteriograms (CPNA), and a high prevalence of scintigraphic perfusion defects has been reported in such patients. ${ }^{1-4}$ The underlying pathophysiological mechanisms remain incompletely understood, but the existence of coronary microvascular dysfunction leading to myocardial ischaemia has been proposed. ${ }^{5}$ The concept of microvascular ischaemia in hypertensive CPNA patients has been supported by evidence of structural and functional microvascular abnormalities ${ }^{7-9}$ and its validity has been generally accepted. In contrast, the notion that chest pain in normotensive CPNA patients (syndrome $\mathrm{X}$ ) is caused by myocardial ischaemia is not universally accepted. Recent studies using stress echocardiography have failed to show regional wall motion abnormalities in normotensive CPNA patients, ${ }^{10-13}$ casting doubts on to the existence of microvascular ischaemia in syndrome X. However, although the diagnostic accuracy of stress echocardiography is well established in coronary artery disease, ${ }^{14}$ its sensitivity is reduced when the diameter of the diseased vessel is less than $2.6 \mathrm{~mm} .{ }^{15}$ Consequently, this technique may not be ideally suited to the investigation of patients who might have microvascular ischaemia. Our aim in the present study was to compare systematically the results of dobutamine stress echocardiography in well matched groups of hypertensive and normotensive CPNA patients with positive exercise electrocardiograms.

\section{Methods}

STUDY PATIENTS

Study patients were recruited from a specialised CPNA clinic at St George's Hospital. Baseline characterisation included electrocardiographic exercise stress testing, transthoracic cross sectional echocardiography, and hyperventilation/ergonovine provocation testing for coronary spasm. All patients gave written informed consent before participation and the local ethics committee approved the study protocol.

Study inclusion criteria were exertional angina, a positive ECG response to exercise stress testing $(0.1 \mathrm{mV}$ horizontal or downsloping ST segment depression $80 \mathrm{~ms}$ after the J point), and a completely normal coronary arteriogram. Patients with evidence of left ventricular hypertrophy, valvar disease, or 
myocardial disease on echocardiography were excluded, as were those who developed chest pain or ECG changes suggesting epicardial coronary artery spasm during provocation testing. Patients with diabetes mellitus, a plasma cholesterol concentration above 6.5 $\mathrm{mmol} / \mathrm{l}$, smokers, or with non-cardiac causes of chest pain were also excluded.

The study population consisted of 33 patients divided into two groups. The first group (group $1 ; \mathrm{n}=17$ ) consisted of patients with a history of hypertension, defined by a diastolic blood pressure $>95 \mathrm{~mm} \mathrm{Hg}$ requiring long term antihypertensive treatment (14 women, three men; mean (SD) age 57 (6) years); the second group (group 2; $n=16$ ) comprised patients with no history of hypertension ( 12 women, four men; mean age 54 (9) years). The mean duration of hypertensive treatment in group 1 was eight years (range three to 17 years). Apart from three patients who had mildly raised plasma creatinine concentrations there were no other secondary manifestations of hypertension. Mean blood pressure in group 1, as measured during the last study visit, was 151 (11) $\mathrm{mm} \mathrm{Hg}$ systolic and 91 (10) $\mathrm{mm} \mathrm{Hg}$ diastolic.

All patients were symptomatic at the time of the study. They predominantly complained of chest pain during exercise with the characteristics of angina pectoris (that is, location, character, radiation, duration, and relief by resting or short acting nitrates). Eleven normotensive patients and eight hypertensive patients also described atypical symptoms including prolonged episodes of chest pain or episodes at rest. The presence of myocardial ischaemia in study patients was investigated by ambulatory electrocardiographic monitoring, dobutamine stress echocardiography, and thallium-201 single photon emission computed tomography (SPECT). All patients discontinued cardioactive drugs for at least 48 hours before examinations.

AMBULATORY ECG MONITORING

All patients underwent 24 hour ambulatory ECG monitoring using a three channel, amplitude modulated recorder (Marquette 8500, Marquette Electronics Inc, Milwaukee, Wisconsin, USA). During monitoring, patients were instructed to keep a log of their activities and symptoms. ST segment analysis of all recordings (Marquette 8000 laser Holter, version 5) was performed independently by two investigators. A significant episode of ECG ischaemia was defined as a period of horizontal or downsloping ST segment depression of $>1$ $\mathrm{mm}$ at $80 \mathrm{~ms}$ after the J point, lasting for more than one minute.

DOBUTAMINE STRESS ECHOCARDIOGRAPHY

The cardiac dimensions were measured by $M$ mode echocardiography according to the recommendations of the American Society of Echocardiography. ${ }^{16}$ Left ventricular mass was determined using the Devereux formula,${ }^{17}$ and the left ventricular mass index was calculated by dividing the left ventricular mass by the body surface area. Left ventricle hypertrophy was diagnosed in the presence of a mass index of $>134 \mathrm{~g} / \mathrm{m}^{2}$ for men and $>110 \mathrm{~g} / \mathrm{m}^{2}$ for women. ${ }^{18}$ Standard tomographic views of the left ventricle were acquired before and during dobutamine infusion, using parasternal long and short axis and four or two chamber projections. The images were continuously recorded on 0.75 inch $(19 \mathrm{~mm})$ videotape and from a separate black and white output, in a digital quad-screen format (Image View, DCR version 1.61, Nova MicroSonics, Allendale, New Jersey, USA) every three minutes and during recovery. Dobutamine was infused in a peripheral vein by incremental doses $(5,10,15,20$, 30 , and $40 \mu \mathrm{g} / \mathrm{kg}$ body weight $/ \mathrm{min}$ ) at three minute intervals. Intravenous atropine (bolus dose $0.6-1.2 \mathrm{mg}$ ) was given if $85 \%$ of the maximum predicted heart rate was not achieved at the maximum infusion rate. A 12 lead ECG was recorded every three minutes, and blood pressure was monitored every minute using an automatic cuff sphygmomanometer. Echocardiograms were reviewed by two experienced observers, unaware of the results of the other studies. Segmental wall motion was assessed by dividing the left ventricle into 16 segments according to the recommendations of the American Society of Echocardiography, ${ }^{19}$ and positivity was defined by the development of a new wall motion abnormality (hypokinesia, akinesia, dyskinesia) or worsening regional wall motion abnormality not present at baseline.

THALLIUM-201 SINGLE PHOTON EMISSION COMPUTERISED TOMOGRAPHY

As part of their clinical characterisation, thallium SPECT was performed in all patients according to a previously published protocol. ${ }^{20}$ Patients were requested to abstain from xanthine containing food and drinks for at least 24 hours before the study. They were given a loading dose of dipyridamole, 0.56 $\mathrm{mg} / \mathrm{kg}$ over four minutes, combined with three minutes of straight leg raising. This was followed by intravenous administration of 2 $\mathrm{mCi}$ of thallium-201 chloride. Imaging was begun within 10 minutes of the administration of the radionuclide and again after three hours, using a large field of view gamma camera (E1-Scint SP6). Images were acquired in an arc of $180^{\circ}$, from the left posterior $45^{\circ}$ oblique to the right anterior $45^{\circ}$ oblique position. Thirty images were taken for every $6^{\circ}$ interval for 45 seconds/view. Filtered back projections were obtained using a ramp filter at a cut off frequency of $0.5 \mathrm{c} / \mathrm{s}$. No attenuation or scatter correction was used. The E1-Scint SP1 computer was used for image reconstruction. Bullseye polar coordinate map images were produced.

All images were assessed independently by two observers without knowledge of the results of other studies. Perfusion defects suggestive of myocardial ischaemia were defined as impaired perfusion with redistribution of at least one segment in the delayed thallium-201 images. The redistribution of the thallium tracer was assessed by visually comparing the immediate with the delayed images. Fixed defects were 
defined as regions with reduced uptake of thallium-201, which persisted on delayed images. Reversible perfusion defects suggestive of myocardial ischaemia were those which showed diminished perfusion during stress but normal perfusion in rest images.

STATISTICAL ANALYSIS

Values are presented as mean (SD) or percentages where appropriate. Between group comparison of continuous data was performed using a two tailed unpaired $t$ test with $\log$ transformation of non-normally distributed variables where necessary. The $\chi^{2}$ or Fisher's exact tests were used as appropriate for comparison of categorical data. A probability $<0.05$ was considered statistically significant.

\section{Results}

Demographic data and clinical characteristics of the patients are presented in table 1 .

\section{AMBULATORY ECG MONITORING}

Three hypertensive patients and two normotensive patients had $T$ wave flattening or inversion on their resting ECG. None of the hypertensive patients satisfied the ECG criteria for left ventricular hypertrophy. ${ }^{21}$ Nine normotensive and eight hypertensive patients had episodes of significant ST segment depression during the monitoring period. There were no

Table 1 Clinical characteristics of the patients

\begin{tabular}{lrrr}
\hline & $\begin{array}{c}\text { Normotensive } \\
(n=16)\end{array}$ & $\begin{array}{c}\text { Hypertensive } \\
(n=17)\end{array}$ & $p$ Value \\
\hline Women/men & $12 / 4$ & $14 / 3$ & 0.69 \\
Age (years) & $54(9)$ & $57(6)$ & 0.39 \\
Postmenopausal women (n) & 10 & 9 & 0.39 \\
Systolic blood pressure (mm Hg) & $127(18)$ & $151(11)$ & $<0.005$ \\
Diastolic blood pressure (mm Hg) & $77(8)$ & $91 \quad(10)$ & $<0.005$ \\
Drug treatment (n) & 12 & 14 & 0.69 \\
$\quad$ Nitrates & 6 & 12 & 0.056 \\
$\quad$ Blockers & 12 & 14 & 0.69 \\
Calcium antagonists & 0 & 5 & 0.04 \\
ACE inhibitors & 0 & 4 & 0.1 \\
Diuretics & 5 & 6 & 0.95 \\
$\quad$ Hormone replacement therapy & & & \\
Exercise stress testing & $6.3(2.0)$ & $5.5(1.2)$ & 0.57 \\
$\quad$ Duration (min) & $4.7(1.9)$ & $4.3(1.6)$ & 0.6 \\
Time to 1 mm ST depression (min) & $1.7(0.7)$ & $1.8(0.6)$ & 0.2 \\
Max ST segment depression (mm) & 12 & 14 & 0.69 \\
Chest pain (n) & & & \\
\hline
\end{tabular}

Values are mean (SD) or $\mathrm{n}$.

ACE, angiotensin converting enzyme.

Table 2 Dobutamine stress echocardiography results in 33 patients

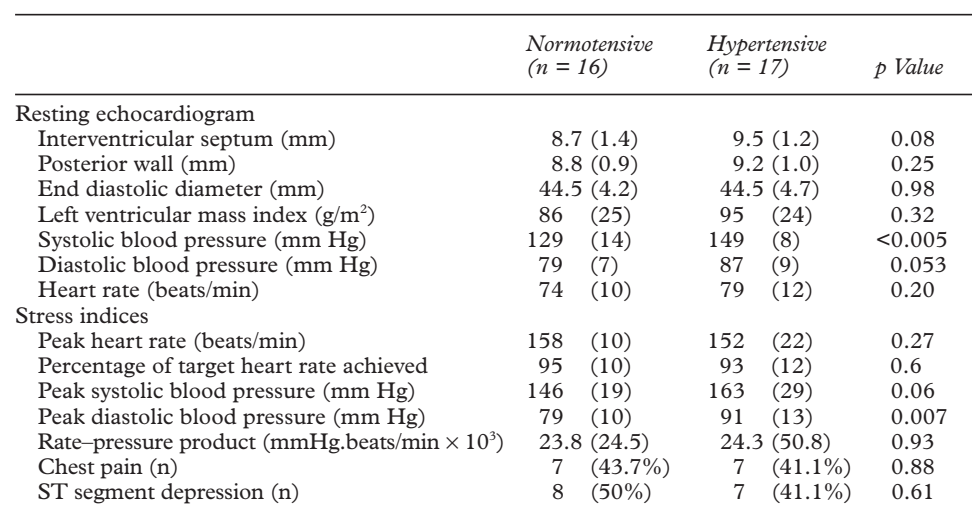

Values are mean (SD) or $\mathrm{n}$. significant differences between the two groups regarding the mean number of ST segment depression episodes (group 1, hypertensive, 8.0 (4.5) $v$ group 2, normotensive, 10.2 (10.0); $\mathrm{p}=0.88)$ or the mean duration of each ST segment depression episode (group 1, 8.6 (7.6) minutes v group 2, 12.0 (11.2) minutes; $\mathrm{p}=0.51)$. The mean total duration of ST segment depression was also similar in the two groups (group 1, 62.4 (53.0) minutes $v$ group 2, 72.8 (52.7) minutes; $\mathrm{p}=0.47$ ).

DOBUTAMINE STRESS ECHOCARDIOGRAPHY All patients had normal left ventricular systolic function at rest and none fulfilled the criteria for ventricular hypertrophy. None of the patients, whether hypertensive or normotensive, had wall motion abnormalities at rest. The interventricular septum was thicker in the hypertensive patients $(9.5(1.2) \mathrm{mm})$ than in the normotensive patients (8.7 (1.4) $\mathrm{mm}$ ), although this difference failed to achieve statistical significance $(p=0.08)$. However, there was no significant difference between the two groups in terms of either posterior wall thickness (group 1, 9.2 (1.0) $\mathrm{mm} v$ group 2, $8.8(0.9) \mathrm{mm} ; \mathrm{p}=0.25$ ) or left ventricular end diastolic dimensions (group 1, 45 (5) $\mathrm{mm} v$ group 2, 45 (4) $\mathrm{mm} ; \mathrm{p}=0.98)$. Compared with the normotensive patients, the hypertensive patients showed a trend towards increased left ventricular mass index (group 1, 95 (24) $\mathrm{g} / \mathrm{m}^{2} v$ group 2, $\left.86(25) \mathrm{g} / \mathrm{m}^{2}\right)$, but the difference did not reach statistical significance $(\mathrm{p}=0.11)$.

Satisfactory echocardiographic imaging was achieved for segmental analysis in all patients. Basal and peak heart rate, blood pressure, and heart rate-blood pressure product during dobutamine stress echocardiography are presented in table 2. The mean percentage of heart rate achieved during dobutamine stress was more than $90 \%$ of target heart rate in both groups. Two patients from each group had a mild hypotensive response to dobutamine infusion but there were no other significant adverse events. Dobutamine infusion reproduced anginal pain in seven normotensive and seven hypertensive patients $(\mathrm{p}=0.88)$. ST segment depression was also recorded in eight normotensive and seven hypertensive patients $(\mathrm{p}=0.61)$, and two hypertensive patients developed transient left bundle branch block at peak stress. In these two patients we observed the characteristic septal wall motion alteration, which lasted as long as left bundle branch block was present. Wall thickening was normal throughout. No ischaemic regional wall motion abnormalities were demonstrated in either group during dobutamine stress echocardiography.

THALLIUM-201 SINGLE PHOTON EMISSION COMPUTERISED TOMOGRAPHY

Eight normotensive patients and 10 hypertensive patients had perfusion abnormalities on thallium SPECT $(p=0.61)$. Thallium defects were similar in both groups. In the normotensive group, seven had transient defects and one had a combination of fixed and transient 
defects. These defects were all observed in the anterior and apical region of the ventricle, except in one patient in whom the defect was located in the inferior wall. In the hypertensive group, seven had transient defects and three had a mixed pattern of fixed and transient defects. All defects in the hypertensive group occurred in anterior wall. There was no clear relation between scintigraphic findings and either chest pain or electrocardiographic changes during dobutamine stress in either group.

\section{Discussion}

In this study, we compared the response to dobutamine stress in two well characterised groups of CPNA patients, one normotensive and one hypertensive, using transthoracic echocardiography. Both groups had anginal pain and ischaemic ECG changes during exercise testing, and in a large proportion scintigraphic perfusion abnormalities were also demonstrated. Despite this evidence of abnormal perfusion and electrocardiographic ischaemia, we failed to demonstrate regional wall motion abnormalities during dobutamine stress echocardiography in either group. Our findings are consistent with those of other groups, which have been unable to show regional wall motion abnormalities during transthoracic stress echocardiography in normotensive CPNA patients. ${ }^{10-13}$ However, although the concept of microvascular ischaemia is more widely accepted in hypertensive patients who present with chest pain despite normal coronary angiograms than in patients with syndrome $\mathrm{X}$, our study does not indicate that abnormal stress echocardiographic findings are any more likely to occur in hypertensive than in normotensive patients. As part of a study to assess the diagnostic accuracy of dobutamine stress echocardiography in hypertensive patients, Senior et al investigated 43 patients with systemic hypertension, anginal chest pain, and positive exercise ECGs and did not find regional wall motion abnormalities during dobutamine stress echocardiography in any of those $(n=14)$ with normal coronary arteriograms. ${ }^{22}$ Interestingly, they also found that regional wall motion abnormalities during dobutamine stress echocardiography were not more likely to occur in hypertensive CPNA patients with left ventricular hypertrophy $(n=9)$ than in those without $(\mathrm{n}=5)$. More recently, Panza et al have used transoesophageal dobutamine stress echocardiography to investigate a group of CPNA patients which included 14 borderline hypertensive individuals and also did not find regional all motion abnormalities, despite the occurrence of chest pain and ischaemic ECG changes during stress. ${ }^{13}$ Although these studies have provided some information about dobutamine stress echocardiography in hypertensive patients with CPNA, our present study is the first to specifically compare stress echocardiographic findings in similar groups of normotensive and hypertensive CPNA patients.
Stress echocardiography is a clinically established technique, which is sensitive and specific for the identification of significant angiographic coronary disease. ${ }^{14}$ The results of the present study support the fact that dobutamine stress echocardiography has a high specificity in the assessment of significant coronary artery stenoses. However, Bartunek et al have recently reported that the sensitivity of stress echocardiography for detecting significant epicardial stenoses is reduced when the diameter of the diseased vessel is less than $2.6 \mathrm{~mm} .{ }^{15}$ Therefore the absence of regional wall motion abnormalities on stress echocardiography in CPNA patients may not necessarily exclude an ischaemic mechanism reflecting microvascular dysfunction. In this context, Maseri et al have previously proposed a model of "patchy" constriction of prearteriolar vessels in CPNA patients resulting in small ischaemic foci. ${ }^{23}$ Such patchy ischaemia might be undetectable by stress echocardiography, not only because of the small size of the ischaemic segments but also because of a tethering effect of neighbouring nonischaemic segments which may induce a passive systolic inward motion.

Despite the absence of significant epicardial coronary stenoses, scintigraphic perfusion defects are often detected in hypertensive CPNA patients, especially (but not entirely) in those with left ventricular hypertrophy. ${ }^{4}$ In our present study, we were able to show scintigraphic abnormalities in over half of the hypertensive CPNA patients without left ventricular hypertrophy. This finding emphasises that the occurrence of scintigraphic defects in hypertensive CPNA patients is not dependent on the presence of left ventricular hypertrophy. It is also established that most patients with uncomplicated hypertension do not have left ventricular hypertrophy, ${ }^{24}$ as in our hypertensive group. Brush et al have also reported anginal chest pain and functional abnormalities of coronary resistance vessels in hypertensive patients in the absence of left ventricular hypertrophy. ${ }^{25}$ Furthermore, Vogt et al found no correlation between reductions in coronary flow reserve and the severity of left ventricular hypertrophy in a study group of more than 200 hypertensive patients. ${ }^{26}$ Thus it is unlikely that myocardial hypertrophy and increased extravascular compression forces are the sole mechanisms responsible for microvascular dysfunction and perfusion abnormalities in hypertensive patients. Structural or functional changes in the coronary microcirculation must also be considered. The evidence for structural changes in hypertensive resistance arteries is well established, ${ }^{7}$ and such changes affecting the wall to lumen ratio of the vessel may have a profound effect on vascular resistance. ${ }^{8} \mathrm{Cap}-$ illary rarefaction ${ }^{9}$ has been demonstrated in hypertensive patients and may represent another important structural change in the microvasculature. Abnormal endothelium dependent vascular relaxation in the coronary resistance vessels has also been found in hypertensive patients. ${ }^{27-30}$ Such endothelial dysfunction may produce inhomogeneity of 
regional myocardial perfusion resulting in localised scintigraphic defects. This hypothesis is supported by the findings of Aguirre et $a l^{31}$ who found a greater reduction of coronary flow reserve in territories with than without scintigraphic ischaemia in hypertensive CPNA patients.

Similar pathophysiological mechanisms involving coronary microvascular abnormalities have been proposed to explain the presence of scintigraphic perfusion defects and coronary flow reserve abnormalities in normotensive CPNA patients. ${ }^{32}{ }^{33}$ Furthermore, both Zeiher et $a l^{34}$ and Hasdai et $a l^{35}$ have shown an association between scintigraphic perfusion defects and impaired regional endothelium dependent vasodilatation of the coronary microcirculation in normotensive CPNA patients. The consistency of findings between hypertensive and normotensive CPNA patients, along with the high prevalence of scintigraphic defects in both groups, suggests that the absence of regional wall motion abnormalities during dobutamine stress echocardiography cannot exclude the existence of patchy myocardial ischaemia secondary to coronary microvascular dysfunction. Such a mechanism has received further support from preliminary findings indicating that increased intracardiac oxidative stress may play a significant pathophysiological role in CPNA patients. ${ }^{36}$ As highlighted by Cannon in a recent editorial, ${ }^{37}$ the presence of endothelial microvascular dysfunction may not necessarily be synonymous with ischaemia. Perfusion abnormalities in patients with microvascular dysfunction may only represent inhomogeneity of blood flow between different myocardial regions without absolute reductions in blood flow. Nevertheless, our findings suggest that this possibility must be considered equally in both normotensive and hypertensive CPNA patients, despite the abundance of pathogenic mechanisms to explain microvascular ischaemia in the latter group.

\section{CONCLUSIONS}

Neither hypertensive nor normotensive CPNA patients develop regional wall motion abnormalities during stress echocardiography. These negative findings may indicate the absence of significant ischaemia in both groups. However, a mild patchy ischaemia secondary to microvascular dysfunction cannot be excluded and may be beyond the detection limit of the technique.

IDC is supported by a fellowship grant from the British Heart Foundation. XG-M is supported by a fellowship of the Spanish Society of Cardiology and the Hospital de la Santa Creu i Sant Pau, Barcelona, Spain.

1 Rosano GM, Peters NS, Kaski JC, et al. Abnormal uptake and washout of thallium-201 in patients with syndrome X and normal appearing scans. Am f Cardiol 1995;75:400-2

2 Berger BC, Abramovitz R, Park EH, et al. Abnormal thallium-201 scans in patients with chest pain and angiographically normal coronary arteries. Am 7 Cardiol 1983;52:365-70.

3 Tweddel AC, Martin W, Hutton I. Thallium scans in syndrome X. Br Heart f 1992;68:48-50.

4 Iriarte $\mathrm{M}$, Caso $\mathrm{R}$, Murga $\mathrm{N}$, et al. Microvascular angina pectoris in hypertensive patients with left ventricular sypertrophy and diagnostic value of exercise
5 Opherk D, Mall G, Zebe H, et al. Reduction of coronary reserve: a mechanism for angina pectoris in patients with arterial hypertension and normal coronary arteries. Circuarterial hypertension

6 Cannon RO, Epstein SE. Microvascular angina as a cause of chest pain with angiographically normal coronary arteries. Am $\mathcal{F}$ Cardiol 1988;61:1338-43.

7 Aalkjaer C, Heagerty AM, Peterson KK, et al. Evidence for increased media thickness, increased neuronal amine uptake and decreased excitation-contraction coupling in isolated resistance vessels from essential hypertensives. Circ Res 1987;61:181-6.

8 Folkow B, Grimby G, Thulesius O. Adaptive structural changes of the vascular walls in hypertension and their relation to the control of the peripheral resistance. Acta Physiol Scand 1958;44:255-72.

9 Gasser P, Buhler FR. Nailfold microcirculation in normotensive and essential hypertensive subjects, as assessed by videomicroscopy. F Hypertens 1992;10:83-6.

10 Picano E, Lattanzi F, Masini M, et al. Usefulness of high dose dipyridamole-echocardiography test for diagnosis of syndrome X. Am f Cardiol 1987;60:508-12.

11 Nihoyannopoulos P, Kaski JC, Crake T, et al. Absence of myocardial dysfunction during stress in patients with syndrome X. F Am Coll Cardiol 1991;18:1463-70.

12 Lanzarini I, Previtali M, Fetiveau R, et al. Results of dobutamine stress echocardiography in patients with dobutamine stress echocardiography in patient
syndrome X. Int 7 Card Imaging 1994;10:145-8.

13 Panza JA, Laurienzo JM, Curiel RV, et al. Investigation of the mechanism of chest pain in patients with angiographically normal coronary arteries using transesophageal dobutamine stress echocardiography. $\mathscr{f}$ Am Coll Cardiol 1997;29:293-301.

14 Marcovitz PA, Armstrong WF. Accuracy of dobutamine stress echocardiography in detecting coronary artery disease. Am f Cardiol 1992;69:1269-73.

15 Bartunek J, Marwick TH, Rodrigues ACT, et al. Dobutamine-induced wall motion abnormalities: correlations with myocardial fractional flow reserve and quantitative coronary angiography. $\mathcal{F} \mathrm{Am}$ Coll Cardiol 1996;27: tive coron $1429-36$.

16 Sahn DJ, DeMaria A, Kisslo J, et al. Recommendations regarding quantitation in M-mode echocardiography: results of a survey of echocardiographic measurements. Circulation 1978;58:1072-83.

17 Devereux RB, Reichek N. Echocardiographic determination of left ventricular mass in man: anatomic validation of the method. Circulation 1977;55:613-18.

18 Hammond IW, Devereux RB, Alderman MH, et al. The prevalence and correlates echocardiographic left ventricular hypertrophy among employed patients with uncomplicated hypertension. F Am Coll Cardiol 1986;7:639-50.

19 American Society of Echocardiography Committee on Standards, Subcommittee on Quantitation of TwoDimensional Echocardiograms. Recommendations for quantitation of the left ventricle by two-dimensional echocardiography. F Am Soc Echocardiogr 1989;2:358-67.

20 Takata J, Couniham PJ, Gane J, et al. Regional thallium-201 washout in hypertrophic cardiomyopathy and its relation to exertional chest pain. Am f Cardiol 1993;72:211-17.

21 Classification of the electrocardiogram for population studies. Minnesota Code for Resting Electrocardiograms. Circulation 1960;21 (annex 1):137-41.

22 Senior R, Basu S, Handler C, et al. Diagnostic accuracy of dobutamine stress echocardiography for detection of coronary heart disease in hypertensive patients. Eur Heart $\mathcal{F}$ 1996;17:289-95.

23 Maseri A, Crea F, Kaski JC, et al. Mechanisms of angina pectoris in syndrome X. F Am Coll Cardiol 1991;17:499506.

24 Liebson PR, Grandits G, Prineas R, et al. Echocardiographic correlates of left ventricular structure among 844 mildly hypertensive men and women in the Treatment of Mild Hypertension Study (TOHMS). Circulation 1993;87: 476-86.

25 Brush JE, Cannon RO, Schenke WH, et al. Angina due to coronary microvascular disease in hypertensive patients
without left ventricular hypertrophy. $N$ Engl $\mathscr{J}$ Med 1988;319:1302-7.

26 Vogt M, Motz W, Strauer BE. Coronary haemodynamics in hypertensive heart disease. Eur Heart $\mathcal{f}$ 1992;13(suppl D): $44-9$.

27 Panza JA, Quyyumi AA, Brush JE, et al. Abnormal endothelium-dependent vascular relaxation in patients
with arterial hypertension. N Engl f Med 1990;323:22-7.

28 Luscher TF. Heterogeneity of endothelial dysfunction in hypertension. Eur Heart 7 1992;13(suppl D):50-5.

29 Egashira K, Suzuki S, Hirooka Y, et al. Impaired endothelium-dependent vasodilation of large epicardial and resistance coronary arteries in patients with essential hypertension. Hypertension 1995;25:201-6.

30 Houghton JL, Davison CA, Kuhner PA, et al. Heterogeneous vasomotor responses of coronary conduit and resistance vessels in hypertension. F Am Coll Cardiol 1998;31: 374-82.

31 Aguirre JM, Rodriguez E, Ruiz de Azua E, et al. Segmentary coronary reserve in hypertensive patients with echocardiographic left ventricular hypertrophy, gammagraphic ischaemia and normal coronary arteries. Eur Heart $f$ 1993; 14(suppl J):25-31.

32 Cannon RO, Watson RM, Rosing DR, et al. Angina caused by reduced vasodilator reserve of the small coronary arteries. $\mathcal{F} \mathrm{Am}$ Coll Cardiol 1983;1:1359-73. 
33 Geltman EM, Henes CG, Sennef MJ, et al. Increased myocardial perfusion at rest and diminished perfusion reserve in patients with angina and angiographically normal coronary arteries. F Am Coll Cardiol 1990;16 586-95

34 Zeiher AM, Krause T, Schachinger V, et al. Impaired endothelium-dependent vasodilation of coronary resistant vessels is associated with exercise-induced myocardial ischemia. Circulation 1995;91:2345-52.
35 Hasdai D, Gibbons RJ, Holmes DR, et al. Coronary endothelial dysfunction in humans is associated with myo$97 ; 96: 3390-5$

36 Buffon A, Santini S, Liuzzo G, et al. Increased lipoperoxidative stress may cause endothelial dysfunction in syndrome X. F Am Coll Cardiol 1997;29(suppl A):986-76.

37 Cannon RO. Does coronary endothelial dysfunction cause myocardial ischemia in the absence of obstructive coronary artery disease? Circulation 1997;96:3251-4.

\section{IMAGES IN CARDIOLOGY}

\section{A pre-excitation growing up over the time}
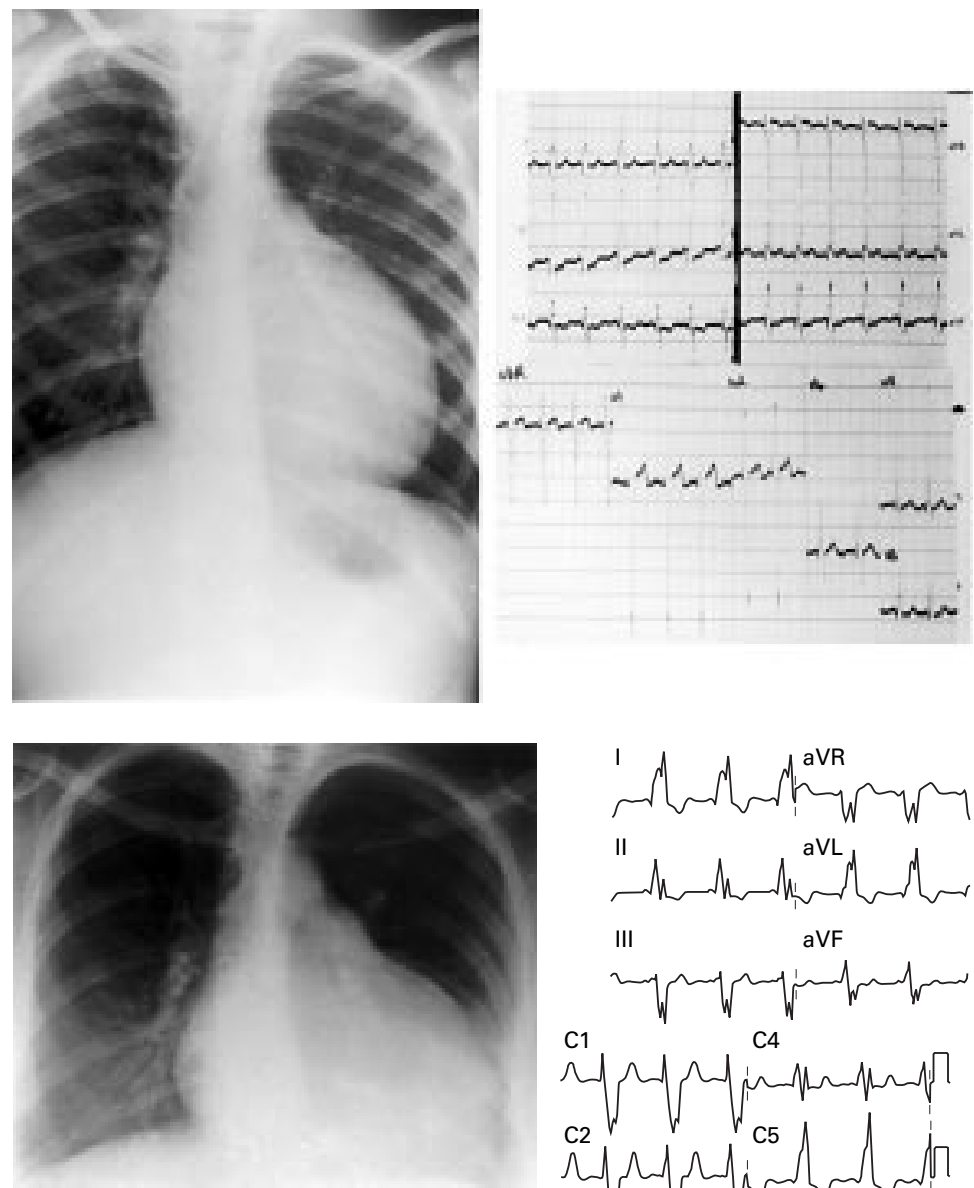

A 35 year old woman was followed up regularly from the age of 8 months, when she was diagnosed with dilated cardiomyopathy secondary to neonatal chickenpox. Aged 5 years, WolffParkinson-White syndrome was recognised based on the presence of a persistent preexcitation pattern and the occurrence of paroxysmal self limited orthodromic re-entrant tachycardia. During follow up, the degree of the pre-excitation increased progressively. The delta-QRS duration lengthened from $130 \mathrm{~ms}$ to $280 \mathrm{~ms}$ as the cardiothoracic ratio increased from 0.57 aged 5 years (top) to 0.64 aged 35 (bottom).

In patients with Wolff-Parkinson-White syndrome, the typical QRS pattern with a slurred initial upstroke is the consequence of the fusion between an earlier activation of some part of the ventricular muscle through the bypass tract (expressed by the typical delta wave) and others normally activated by the normal atrioventricular (AV) conduction system.

In our case, the progression of the cardiomyopathy, unquestionably related to increasing myocardial fibrosis, resulted in delayed conduction down the normal route. Thus, a greater part of the ventricles was activated through the anomalous bundle. Consequently, the progressive increase in the degree of the pre-excitation in a damaged muscle devoid of Purkinje fibres, as normally occurs in the basal portions of the ventricles, explains the widening and bizarre configuration of the delta-QRS complex.

The appearance of the relatively narrow QRS (140 ms) during the tachycardia gives indirect support to the interpretation that the amount of pre-excited muscle determines the broad and distorted ventricular complex.

BERARDO SARUBBI

AMALIA ELIZARI JANE SOMERVILLE 